\title{
Removing Space Weather Influence
}

\author{
Janis BALODIS $^{1}$, Inese VARNA ${ }^{1}$, Madara NORMAND $^{1,2}$ \\ ${ }^{1}$ Institute of Geodesy and Geoinformatics, University of Latvia, \\ Raina blv.19, Riga, LV-1586, Latvia \\ ${ }^{2}$ Faculty of Building and Civil Engineering, Riga Technical University, \\ Kipsalas 6A/B, Riga, LV-1048, Latvia \\ janis.balodis@lu.lv, inese.varna@lu.lv, madara.normanda@lu.lv
}

\begin{abstract}
The space weather impact on GNSS positioning, navigation and timing has been recognised as a serious threat and this problem currently is included in the most important research programmes worldwide.The objective of this paper is to check the space weather impact on the CORS stations. Obviously, they are mainly affected by space weather due to the predominantly highly elevated placement of antenna. The GNSS daily observation records which were splitting in 4 hour records and additionally each of 4 hour records were splitting in 485 minute records. Each newly obtained record was processed. The results of the average values from 48 5-minute kinematic solutions (5-min) were compared with solutions of corresponding 4 hour (4h) continuous static observation solution results. The comparison of $4 \mathrm{~h}$ static observation solutions with splitting, filtering and averaging 48 5-minute kinematic solutions. It gives the possibility to improve the solution accuracy by removing the space weather influenced spikes and outliers.
\end{abstract}

Keywords: GNSS, EUREF, space weather, Bernese software 5.2, GNSS/levelling points

\section{Introduction}

The space weather impact on GNSS positioning, navigation and timing has been recognised as a serious threat (WEB(a); WEB(b); (Jinyun et al., 2015); (Zakharenkova et al., 2016). This problem is included in the most important research programmes worldwide $\mathrm{WEB}(\mathrm{c})$; $\mathrm{WEB}(\mathrm{d})$; WEB(b); WEB(e); (Béniguel et al., 2017). Many researchers and institutions have discovered that geomagnetic storms, sunspots and huge solar flares are the main sources for the unexpected space weather performances affecting the radio signal propagation in outer space of the Earth. (WEB (f); WEB (b); Sreeja, 2016). The space weather phenomenon is interpreted as solar flare associated solar radio burst and small-scale time-varying plasma irregularities that introduce 
amplitude and phase fluctuations in the received signal, a phenomenon known as scintillation (Sreeja, 2016). Solar and geomagnetic activities are the most important error sources in GNSS related positioning tasks (Astafyeva et al., 2015; Cherniak et al., 2015). One of these tasks is the determination of ellipsoidal heights (h) for so called GNSS/levelling points which are used to tie the gravitational geoid model to the framework of national levelling network (Morozova et al., 2017). GNSS 4h static observations have been carried out by the staff of the Institute of Geodesy and Geoinformatics (GGI) at the sites of GNSS/levelling points. The GNSS positioning reduction has been performed in the framework of EUREF reference network EPN (WEB (g)) by using Bernese 5.2 software (Dach et al., 2015). GGI produced software packages for data analysis and Helmert transformation has been applied to reduce obtained positions to the epoch 2015.0 which had been chosen for GGI quasi-geoid modelling as a basic epoch (Morozova et al., 2017). The continuously operating reference station (CORS) networks LatPos (Zvirgzds, 2005; WEB (h)) and EUPOS ${ }^{\mathbb{R}}$ Riga (Balodis et al., 2010; WEB (i)) are used for analysis of accuracy of 4h GNSS static observation results.

The CORS stations of Latvia are operational in the time span of 11 years. For each station the International Terrestrial Reference Frame coordinates were determined from long span observation time series and they can be reduced to needed epoch T, i.e. in this particular case study: 2015.0. The set $S$ of $n=30$ stations with subsets of coordinates for each station are denoted by $s_{i}$, correspondingly:

$$
S=\left\{s_{1}, s_{2}, \ldots, s_{n}\right\}
$$

where $\quad s_{i}=\left\{X_{i}, Y_{i}, H_{i}, T\right\}, i=1,2, \ldots, n$.

Plane coordinates $X_{i}, Y_{i}, H_{i}$ denote North $(X)$, East $(Y)$ and ellipsoidal height Up $(H)$ which are converted from Cartesian coordinates of epoch $T$ for each CORS station correspondingly.

The 30 day continuous observation recorded log files of all CORS stations were analyzed by splitting them in 4 hour sessions (4h). The computation of coordinates was performed for each of the above mentioned sessions by applying the Bernese 5.2 software in framework of 9 nearest EPN (European Permanent Network) stations $(\mathrm{Web}(\mathrm{g}))$. The results were converted from Cartesian coordinates to plane coordinates $x, y, h$ (North, East, Up), where $h$ means ellipsoidal height for each $4 \mathrm{~h}$ session. The set $P$ of $4 \mathrm{~h}$ observation results (further mentioned also as set " $4 \mathrm{~h}$ ") is obtained with subsets $p_{i j k}$ of coordinates:

$$
P=\left\{p_{i j 1}, p_{i j 2}, \ldots, p_{i j k}\right\}, i=1,2, \ldots, 30 ; j=1,2, \ldots, 30 ; k=1,2, \ldots, 6,
$$

where $p_{i j k}=\left\{x_{i j k}, y_{i j k}, h_{i j k}, t_{i j k}\right\}$.

In period of 30 days, 6 times of 4 h sessions per day forms 180 observation sessions for each station. The epoch $t_{i j k}$ is an average epoch of the session.

But the splitting and following Bernese computation was continued by creating 5min solutions $a_{i j k l}$. Accordingly, the set $A$ of 5-min session solutions was obtained: 


$$
A=\left\{a_{i j k 1}, a_{i j k 2}, \ldots, a_{i j k 48}\right\}, i=1,2, \ldots, 30 ; j=1,2, \ldots, 30 ; k=1,2, \ldots, 6,
$$

where $a_{i j k l}=\left\{x_{i j k l}^{\prime}, y^{\prime}{ }_{i j k l}, h^{\prime}{ }_{i j k l}, t^{\prime}{ }_{i j k l}\right\} \in A, \quad l=1,2, \ldots, 48$.

Further the set $A$ is mentioned also as set "5-min".

It is possible to perform some simple analysis in order to identify the space weather affected solutions.

\section{Space weather affected solutions}

The GNSS observation solutions of 5-min GNSS observations at the Latvian CORS stations in December 2016 have been chosen for analysis. Checking the list of strongest geomagnetic storms (WEB $(\mathrm{j})$ ) it was concluded that no strong geomagnetic storms were fixed in December 2016 (Table 1). According to the Table 1 Ap index is rather low and $\mathrm{Kp}$ index just occasionally exceeds $5+$ which is a threshold to observe the aurora in Latvian latitudes. However, in Nordic countries the $\mathrm{Kp}$ index with value $\geq 3+$ is meaningful (Sreeja, 2016).

Table 1. Geomagnetic storms in December 2016 (WEB (j))

\begin{tabular}{cccccccccccc}
\hline$\#$ & \multirow{2}{*}{ Date } & Ap & $\begin{array}{c}\mathbf{0 0 -} \\
\mathbf{0 3 h}\end{array}$ & $\begin{array}{c}\mathbf{0 3}- \\
\mathbf{0 6 h}\end{array}$ & $\begin{array}{c}\mathbf{0 6}- \\
\mathbf{0 9 h}\end{array}$ & $\begin{array}{c}\mathbf{0 9 -} \\
\mathbf{1 2 h}\end{array}$ & $\begin{array}{c}\mathbf{1 2 -} \\
\mathbf{1 5 h}\end{array}$ & $\begin{array}{c}\mathbf{1 5}- \\
\mathbf{1 8 h}\end{array}$ & $\begin{array}{c}\mathbf{1 8}- \\
\mathbf{2 1 h}\end{array}$ & $\begin{array}{c}\mathbf{2 1 -} \\
\mathbf{0 0 h}\end{array}$ & $\begin{array}{c}\text { Kp } \\
\text { max }\end{array}$ \\
\hline 1 & 2016.12 .08 & $\mathbf{2 1}$ & $3+$ & 4 & $3-$ & $3-$ & $3-$ & 4 & $4+$ & 4 & $4+$ \\
2 & 2016.12 .09 & $\mathbf{2 4}$ & 4 & 2 & $3+$ & $4-$ & 3 & $4-$ & $5-$ & $5-$ & $5-$ \\
3 & 2016.12 .21 & $\mathbf{2 3}$ & 2 & 2 & $1+$ & 3 & $3+$ & 6 & 4 & 4 & 6 \\
4 & 2016.12 .22 & $\mathbf{2 2}$ & $5-$ & $4+$ & $3+$ & 3 & 3 & $3-$ & 4 & 3 & $5-$ \\
5 & 2016.12 .23 & $\mathbf{1 9}$ & 3 & 4 & $3-$ & $3+$ & 3 & $3+$ & 4 & $4-$ & 4 \\
6 & 2016.12 .25 & $\mathbf{2 0}$ & $3+$ & $3+$ & 2 & $4-$ & 4 & 4 & 4 & $3-$ & 4 \\
7 & 2016.12 .26 & $\mathbf{2 0}$ & $5-$ & $3+$ & $3+$ & 3 & $4-$ & $4-$ & $3-$ & $3+$ & $5-$ \\
\hline
\end{tabular}

The phenomenon of GNSS space weather affected solutions is checked at the Latvian CORS stations LatPos and EUPOS ${ }^{\circledR}$-Riga by performing Eq.4, Eq.5 and Eq.6:

$$
\begin{aligned}
& \mathrm{D} x_{i j k l}=x_{i j k l}^{\prime}-x_{i}, \\
& \mathrm{D} y_{i j k l}=\mathrm{y}_{i j k l}^{\prime}-y_{i}, \\
& \mathrm{D}_{i j k l}=h_{i j k l}^{\prime}-H_{i} .
\end{aligned}
$$

If at least one of the kinematic 5-min GNSS observation solution discrepancies according Eq.4- 6 exceeds +10 or $-10 \mathrm{~cm}$ thresholds the events are fixed and they are presented in Table 2. The epoch difference $\left(t_{i j k l}-T\right)$ doesn't play important role in these coordinate differences. The epoch is important for fixing the time when events occurred. The disturbed results are fixed mostly near the dawn and/or after the dusk. For example, in $8^{\text {th }}$ December simultaneously in 8 station observations disturbed results were fixed exceeding the threshold of $10 \mathrm{~cm}$ in at least one of North, East, Up components. Most of the occurrences occasionally happened in one station for short time. 
Table 2. Outlying discrepancy events at the CORS stations in DEC 2016

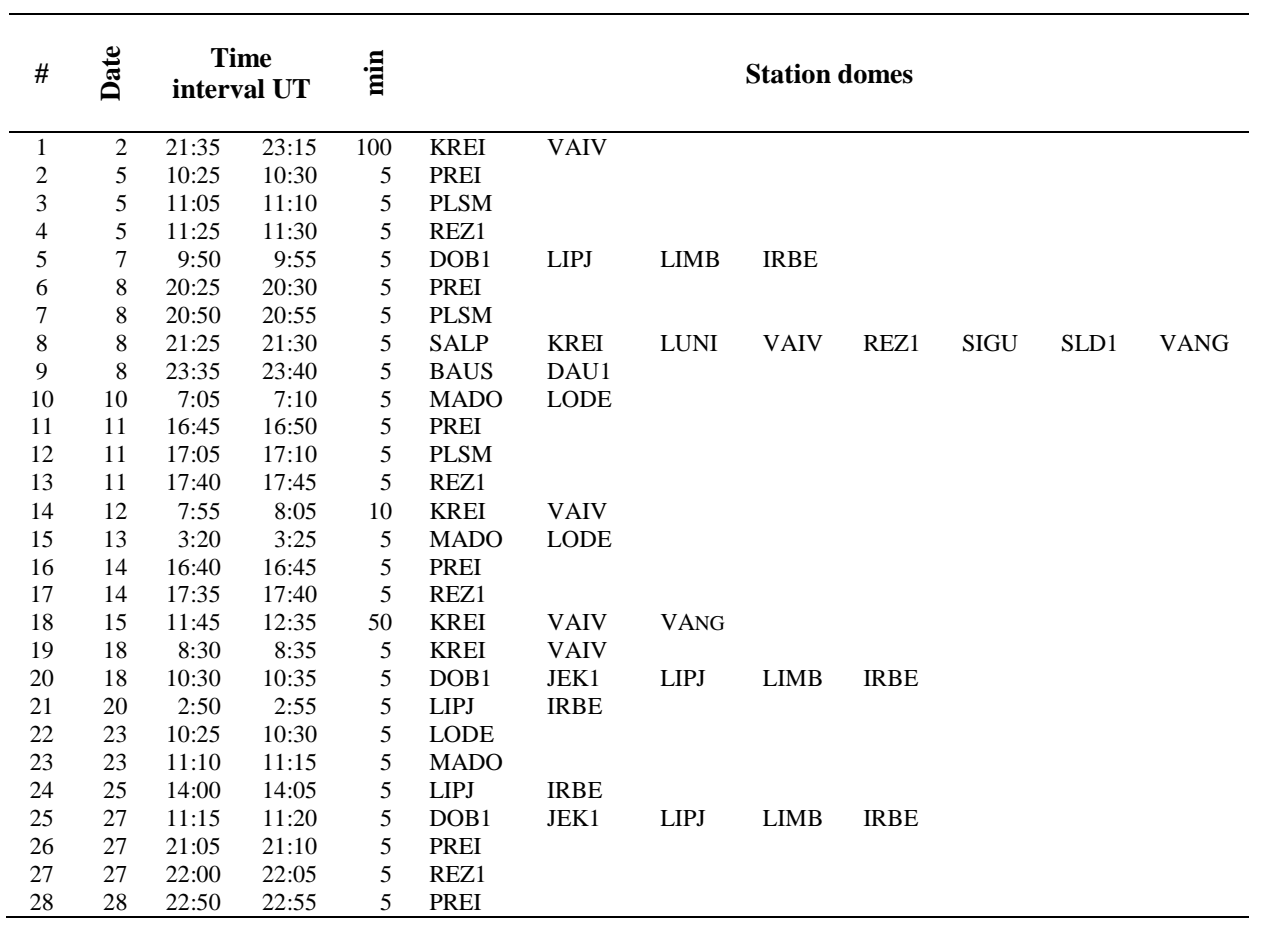

The typical discrepancy values are shown in Table 3. It is noticeable that there are some groups of stations with similar values of discrepancies. Stations (Domes) KREI, LUNI, VAIV, SALP, and VAIV are located in Riga city and its surroundings. Stations REZ1 and SIGU are located to the East from Riga, station SLD1 to the West from Riga. All stations of this set are located approximately in the same geographical latitude.

Table 3. Typical discrepancy values caused by space weather influence

\begin{tabular}{lllllll}
\hline$\#$ & Domes & Date & Time & Dx(m) & Dy(m) & Dh(m) \\
\hline 1 & SALP & 8 & $21: 25$ & -1.584 & -4.103 & 15.347 \\
2 & KREI & 8 & $21: 25$ & -1.642 & -4.056 & 15.389 \\
3 & LUNI & 8 & $21: 25$ & -1.613 & -4.058 & 15.383 \\
4 & VAIV & 8 & $21: 25$ & -1.618 & -3.983 & 15.411 \\
5 & VANG & 8 & $21: 25$ & -1.64 & -4.121 & 15.375 \\
6 & REZ1 & 8 & $21: 25$ & -0.04 & 0.772 & 1.066 \\
7 & SIGU & 8 & $21: 25$ & -0.055 & 0.803 & 1.063 \\
8 & SLD1 & 8 & $21: 25$ & -0.039 & 0.833 & 1.027 \\
\hline
\end{tabular}

\section{Comparison of $4 \mathrm{~h}$ results with an average from 48 splitted 5-min results}

The data set of 4 h solutions for 30 Latvian CORS stations $(S)$ and the GNSS observation records were selected for 30 days of December 2016. The data static mode processing 
has been performed using Bernese software 5.2 and EUREF reference data for all of the 4h GNSS observation record set (5400 solutions of $\left.p_{i j k}=\left\{x_{i j k}, y_{i j k}, h_{i j k}, t_{i j k}\right\}\right)$. Coordinates of set $S$ belong to the epoch 2015.0, 4h set belongs to different epochs of December 1 till December 30, $n=30$. According Eq.1-2:

$$
\begin{gathered}
X_{i}, Y_{i}, H_{i} \in S, \\
x_{i j k}, y_{i j k}, h_{i j k} \in \mathrm{P} ; \mathrm{i}=1,2, \ldots 30 ; \mathrm{j}=1,2, \ldots, 30 ; \mathrm{k}=1,2, \ldots, 6 .
\end{gathered}
$$

The kinematic mode (KIN) solutions (Dach et al, 2015) for all of the subsets $\mathrm{a}_{\mathrm{ijkl}}$, i.e. 5-min set of observation records (43200 solutions of $a_{i j k l}=\left\{x_{i j k l}^{\prime}, y_{i j k l}^{\prime}, h_{i j k l}^{\prime}, t_{i j k l}^{\prime}\right\}$ ) have been calculated using Bernese software 5.2 and the same EUREF reference data as before.

$x_{i j k l}^{\prime}, y_{i j k l}^{\prime}, h_{i j k l}^{\prime} \in A ; \mathrm{i}=1,2, \ldots 30 ; \mathrm{j}=1,2, \ldots, 30 ; \mathrm{k}=1,2, \ldots, 6 ; l=1,2, \ldots, 48$

The average values have been computed (Eq.10) for all of the subsets of 485 -min solutions, correspondingly:

$$
\bar{x}_{i j k}=\frac{\sum_{l=1}^{48} x_{i j k l}}{48}, \bar{x}_{i j k} \in 5-\min .
$$

The average monthly values have been computed (Eq.11) for all of the CORS stations, correspondingly:

$$
\mathrm{d} x_{i}=\frac{\sum_{j=1}^{30} \sum_{k=1}^{6}\left(x_{i j k-} \bar{x}_{i j k}\right)}{180} .
$$

Similar calculations of Eq.10 and Eq.11 have been done for the East and Up components.

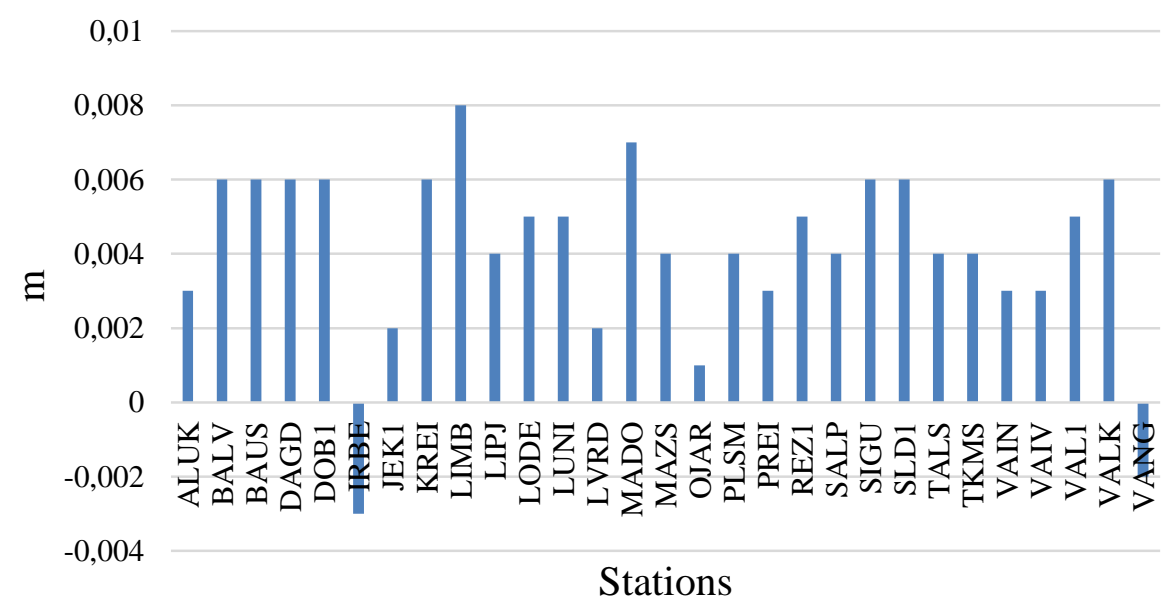

Fig.1. Monthly Up differences between 4 h solutions and average of 48 5-min solutions 
Because of the particular interest of the ellipsoidal height determination (Morozova et al., 2017), further more attention will be paid to disturbances of Up component. The differences of the mean monthly values for Up component are depicted in the histogram of Fig.1.

In order to estimate the time series of all of the monthly discrepancies the monthly standard deviations (STDV) have been computed by applying Eq.12 for solutions of $4 \mathrm{~h}$ set (Eq.7 and Eq.8) and by Eq.13 for 5-min solutions obtained in Eq.10. The compared results are depicted in Fig.2-4.

$$
\begin{gathered}
\sigma_{i}^{\prime}=\sqrt{\frac{\sum_{j=1}^{30} \sum_{k=1}^{6}\left(\bar{x}_{i j k}-X_{i}\right)^{2}}{180}, \sigma^{\prime}}{ }_{i} \in 5-\min \\
\sigma_{i}=\sqrt{\frac{\sum_{j=1}^{30} \sum_{k=1}^{6}\left(x_{i j k}-X_{i}\right)^{2}}{180}}, \sigma_{i} \in 4 h
\end{gathered}
$$

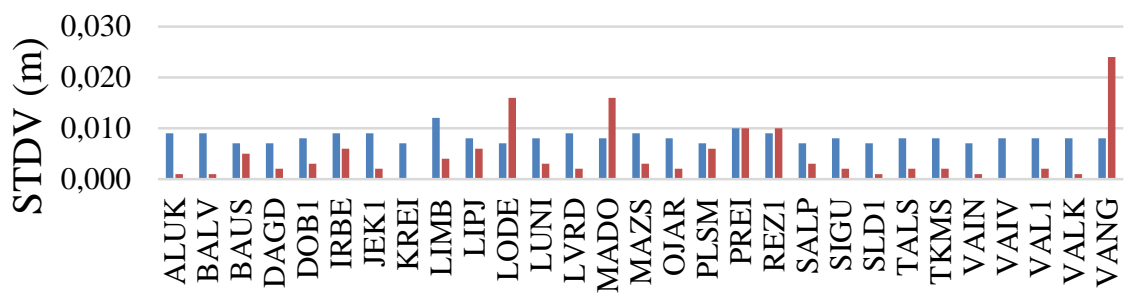

Stations

$\square$ 4h $\square$-min

Fig.2. Comparison of $4 \mathrm{~h}$ Northing STDV $(\sigma)$ and STDV $\left(\sigma^{\prime}\right)$ of average from 5-min solutions Northing. KREI and VAIV 485 -min outlying solutions are excluded

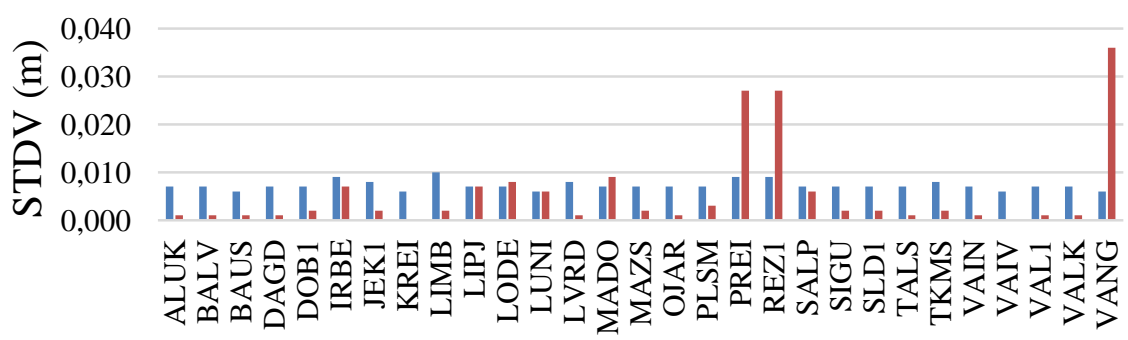

Stations

$\square$ 4h $=5$-min

Fig.3. Comparison of $4 \mathrm{~h}$ Easting STDV $(\sigma)$ and $\operatorname{STDV}\left(\sigma^{\prime}\right)$ of average from 5-min solutions Easting. KREI and VAIV 48 5-min outlying solutions are excluded 


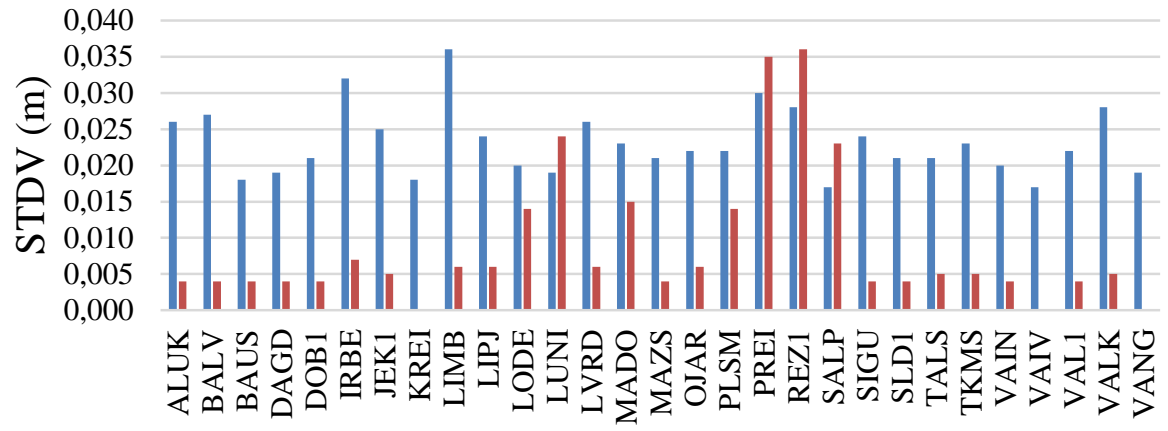

Stations

4h $\quad$ 5-min

Fig.4. Comparison of 4h Up STDV $(\sigma)$ and STDV $\left(\sigma^{\prime}\right)$ of average of 5-min solutions Up. KREI, VAIV and VANG 48 5-min outlying solutions are excluded

There were too large discrepancies in few Northing and Easting components in the solutions for KREI and VAIV stations and for Up component for KREI, VAIV and VANG stations, correspondingly. The most attention in this research is paid to the Up component. Most of the standard deviations of Up component are less than $2 \mathrm{~cm}$. Most of the standard deviations of Northing and Easting components are less than $1 \mathrm{~cm}$. However, in the set of 5-min solutions there are some spikes and even some outliers which are not included in histograms of Fig.2-4. In spite of this, in many cases the 5-min solutions are better than $4 \mathrm{~h}$ solutions.

In Fig.5 the amplitudes of $h_{\max }-h_{\min }$ are depicted for each of the station, correspondingly.

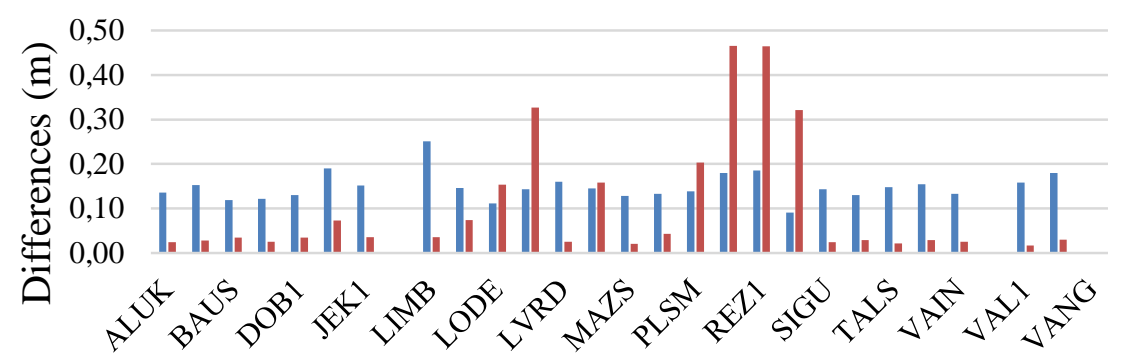

Stations

MAX-MIN 4h $\quad$ MAX-MIN 5-min

Fig.5. Comparison $h_{\max }-h_{\min }$ between $4 \mathrm{~h}$ solution and average of 48 5-min solutions. KREI, VAIV and VANG 48 5-min outlying solutions are excluded 
After estimating the data in Fig.5 it is concluded that the results of the 5-min set have a larger dispersion of amplitudes $\left(h_{\max }-h_{\min }\right)$. Almost all of the Up differences are positive. The differences are very large - up to $50 \mathrm{~cm}$.

\section{Removing spikes and outliers in 5-min solutions}

The attempt to increase the precision of 5-min average values Eq.10 has been applied by removing outlying values of 5-min subset solutions with a threshold of $10 \mathrm{~cm}$ in solutions of set $A$. The success of observation filtering in 4 h static Bernese solutions is not a subject for discussion in this paper. The comparison of repeatedly obtained standard deviations according to the Eq. 12 with a filtered data of set $A$ are depicted in Fig.6-8. The improvements are meaningful because the space weather affected 5-min solutions are removed now. Even KREI, VAIV and VANG 5-min solutions are good quality now.

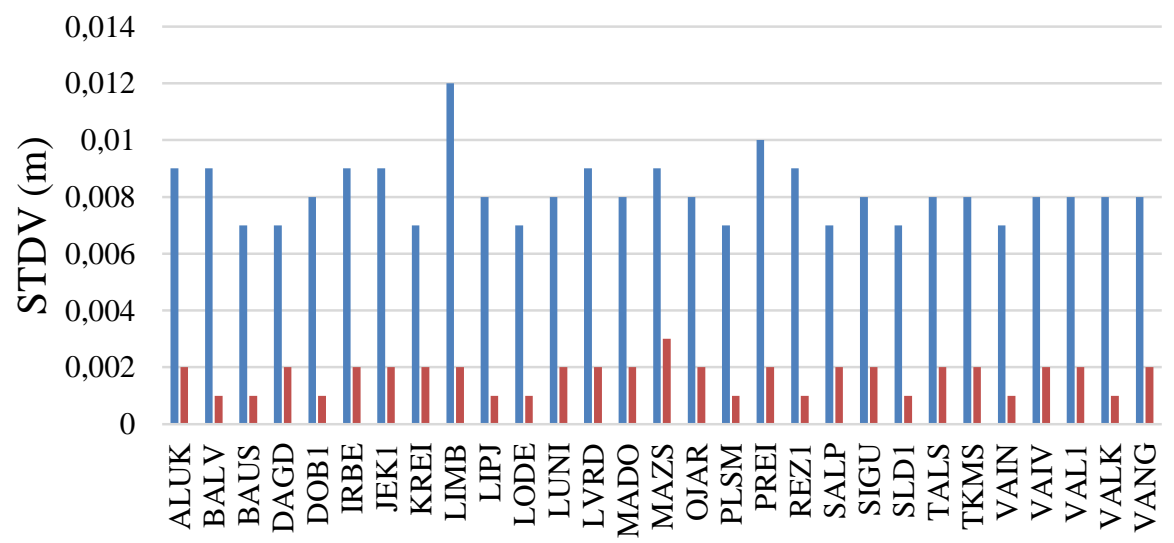

Stations

-4h STDV $\quad$ 5-min STDV

Fig.6. Comparison of $4 \mathrm{~h}$ Northing STDV $(\sigma)$ and STDV $\left(\sigma^{\prime}\right)$ of average of 5-min Northing solutions after filtering with $10 \mathrm{~cm}$ threshold 


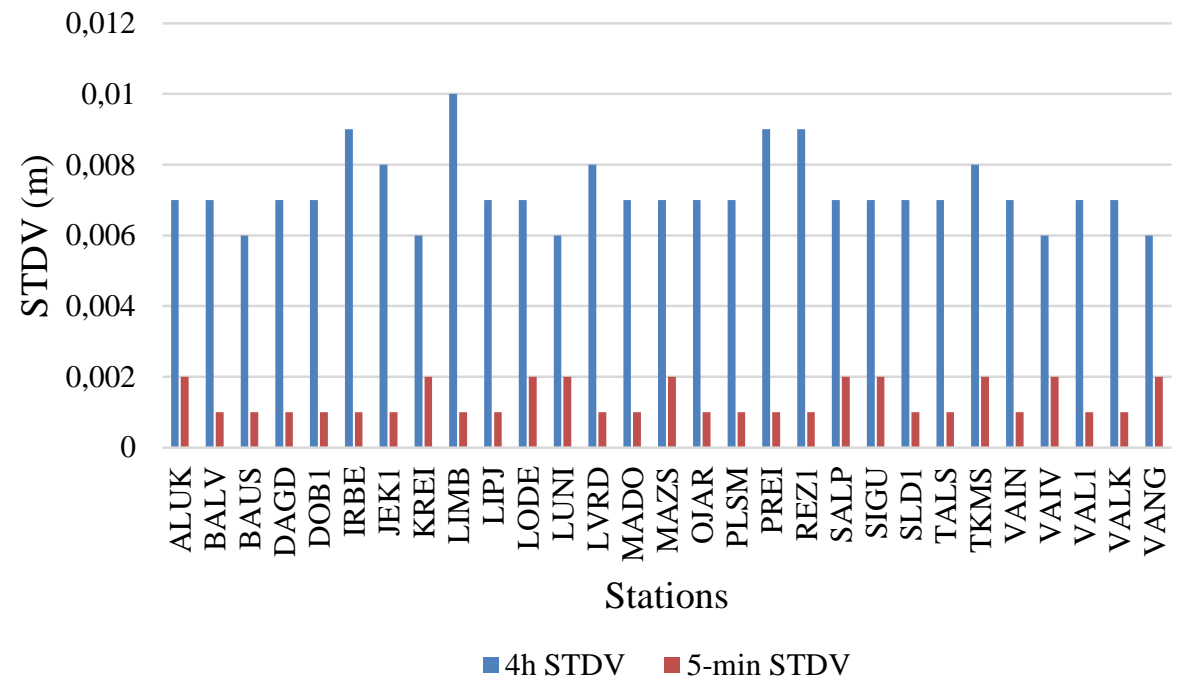

Fig.7. Comparison of 4h Easting STDV $(\sigma)$ and STDV $\left(\sigma^{\prime}\right)$ of average of 5-min Easting solutions after filtering with $10 \mathrm{~cm}$ threshold

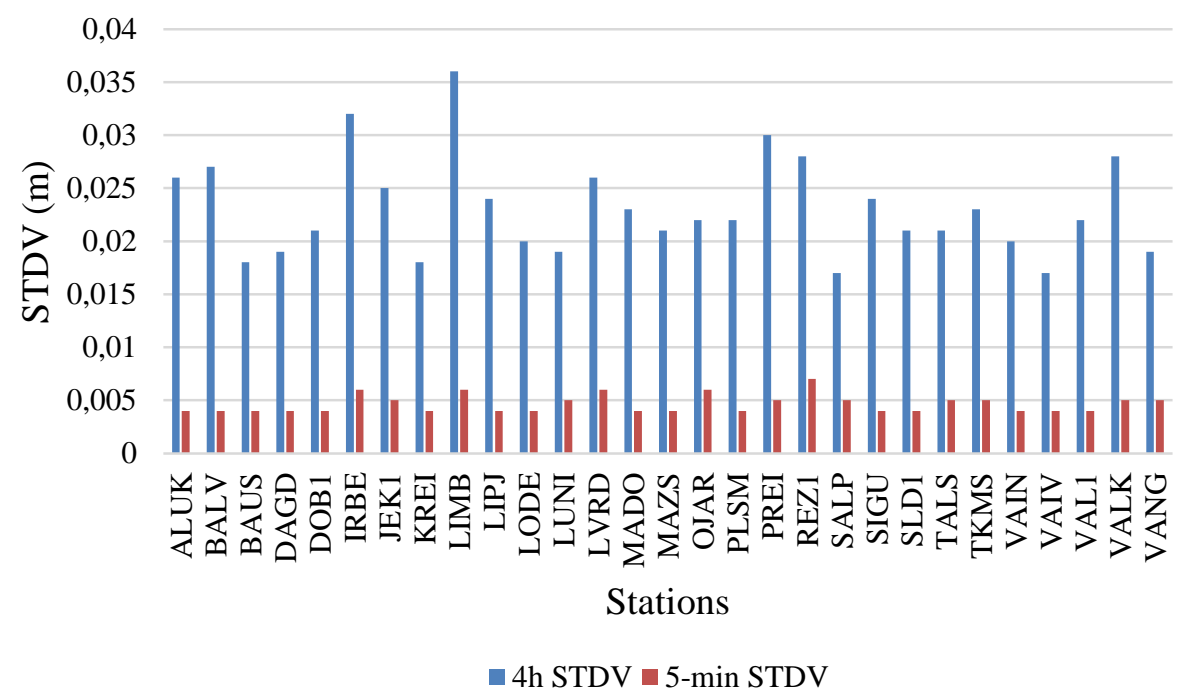

Fig.8. Comparison of $4 \mathrm{~h} \operatorname{Up} \operatorname{STDV}(\sigma)$ and $\operatorname{STDV}\left(\sigma^{\prime}\right)$ of average of 5-min Up solutions after filtering with $10 \mathrm{~cm}$ threshold 


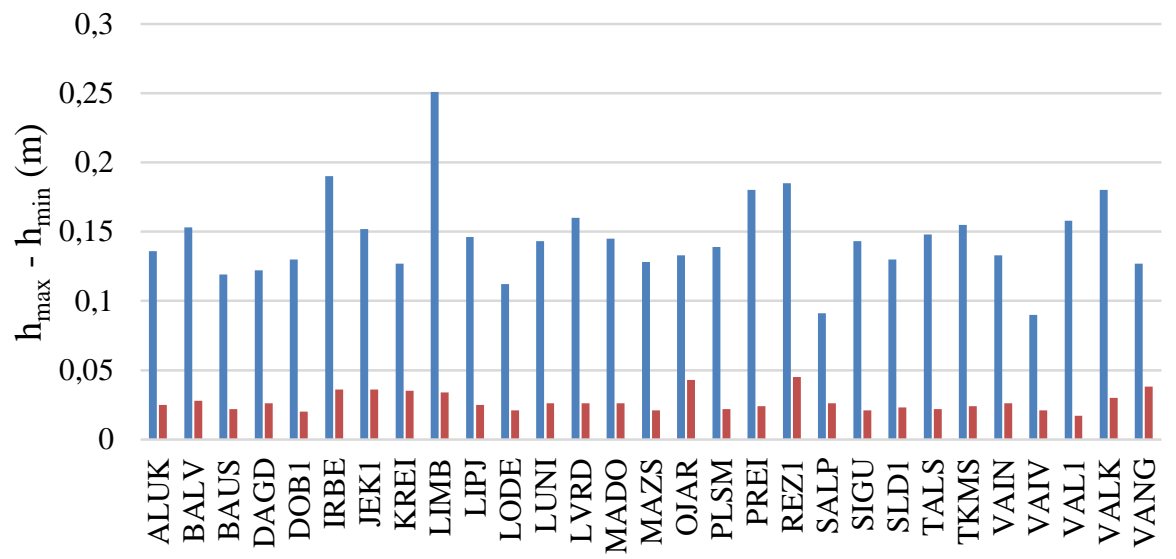

Stations

$\square$ 4h Av.48 5-min

Fig.9. Comparison of $h_{\max }-h_{\min }$ between $4 \mathrm{~h}$ solution and average of 5-min after filtering with $10 \mathrm{~cm}$ threshold

Table 4. Monthly error distribution statistics for 4h, 5-min and filtered 5-min Up solutions

\begin{tabular}{|c|c|c|c|c|c|c|c|c|c|c|c|c|}
\hline \multirow[b]{2}{*}{ Dome } & \multicolumn{3}{|l|}{$4 h$} & \multicolumn{4}{|c|}{ 5-min } & \multicolumn{4}{|c|}{$\begin{array}{l}\text { 5-min } \\
\text { filtered }\end{array}$} & \multirow[b]{2}{*}{$\begin{array}{l}\text { MAX } \\
\text {-MIN }\end{array}$} \\
\hline & STDV & ASIM & EXSC & $\begin{array}{l}\text { MAX } \\
\text {-MIN }\end{array}$ & STDV & ASIM & EXSC & $\begin{array}{l}\text { MAX } \\
\text {-MIN }\end{array}$ & STDV & ASIM & EXSC & \\
\hline ALUK & 0.026 & -0.483 & 3.407 & 0.136 & 0.004 & -0.191 & 3.098 & 0.025 & 0.004 & -0.168 & 3.045 & 0.025 \\
\hline BALV & 0.027 & 0.065 & 3.308 & 0.153 & 0.004 & -0.084 & 3.633 & 0.028 & 0.004 & -0.028 & 3.656 & 0.028 \\
\hline BAUS & 0.018 & 0.251 & 3.427 & 0.119 & 0.004 & -0.710 & 6.350 & 0.035 & 0.004 & -0.007 & 2.784 & 0.022 \\
\hline DAGD & 0.019 & 0.404 & 4.543 & 0.122 & 0.004 & 0.595 & 4.288 & 0.026 & 0.004 & 0.633 & 4.393 & 0.026 \\
\hline DOB1 & 0.021 & 0.106 & 3.540 & 0.130 & 0.004 & -0.112 & 5.420 & 0.035 & 0.004 & 0.248 & 2.957 & 0.020 \\
\hline IRBE & 0.032 & -0.358 & 3.937 & 0.190 & 0.007 & 0.424 & 10.45 & 0.073 & 0.006 & -0.304 & 4.325 & 0.036 \\
\hline JEK1 & 0.025 & -0.251 & 3.394 & 0.152 & 0.005 & -0.664 & 4.890 & 0.036 & 0.005 & -0.711 & 5.168 & 0.036 \\
\hline KREI & 0.018 & -0.693 & 5.200 & 0.127 & 0.158 & -5.188 & 85.308 & 2.621 & 0.004 & -0.932 & 8.087 & 0.035 \\
\hline LIMB & 0.036 & 0.120 & 3.838 & 0.251 & 0.006 & -0.151 & 3.235 & 0.036 & 0.006 & 0.031 & 2.841 & 0.034 \\
\hline LIPJ & 0.024 & 0.406 & 3.604 & 0.146 & 0.006 & -0.374 & 17.509 & 0.074 & 0.004 & 0.102 & 3.264 & 0.025 \\
\hline LODE & 0.020 & 0.372 & 3.281 & 0.112 & 0.014 & -8.227 & 75.939 & 0.154 & 0.004 & 0.352 & 2.836 & 0.021 \\
\hline LUNI & 0.019 & -0.196 & 4.344 & 0.143 & 0.024 & -12.608 & 167.65 & 0.327 & 0.005 & -0.078 & 2.898 & 0.026 \\
\hline LVRD & 0.026 & 0.111 & 3.433 & 0.160 & 0.006 & -0.370 & 2.642 & 0.026 & 0.006 & -0.358 & 2.649 & 0.026 \\
\hline MADO & 0.023 & -0.438 & 4.030 & 0.145 & 0.015 & -7.947 & 72.636 & 0.158 & 0.004 & 0.473 & 3.397 & 0.026 \\
\hline MAZS & 0.021 & 0.724 & 4.280 & 0.128 & 0.004 & 0.409 & 2.841 & 0.021 & 0.004 & 0.443 & 2.939 & 0.021 \\
\hline OJAR & 0.022 & -0.077 & 3.277 & 0.133 & 0.006 & -0.993 & 5.249 & 0.043 & 0.006 & -1.051 & 5.364 & 0.043 \\
\hline PLSM & 0.022 & -0.079 & 3.677 & 0.139 & 0.014 & -11.052 & 140.94 & 0.203 & 0.004 & 0.329 & 2.795 & 0.022 \\
\hline PREI & 0.030 & 0.320 & 3.520 & 0.180 & 0.035 & -10.671 & 126.18 & 0.465 & 0.005 & -0.194 & 2.478 & 0.024 \\
\hline REZ1 & 0.028 & 0.466 & 4.224 & 0.185 & 0.036 & -10.225 & 117.99 & 0.464 & 0.007 & -0.893 & 5.125 & 0.045 \\
\hline SALP & 0.017 & -0.123 & 2.719 & 0.091 & 0.023 & -12.555 & 166.74 & 0.321 & 0.005 & -0.067 & 2.962 & 0.026 \\
\hline SIGU & 0.024 & 0.287 & 3.665 & 0.143 & 0.004 & -0.499 & 3.050 & 0.025 & 0.004 & -0.405 & 2.693 & 0.021 \\
\hline SLD1 & 0.021 & 0.276 & 3.621 & 0.130 & 0.004 & -0.321 & 4.159 & 0.029 & 0.004 & 0.027 & 3.072 & 0.023 \\
\hline TALS & 0.021 & 0.325 & 4.779 & 0.148 & 0.005 & 0.304 & 2.665 & 0.022 & 0.005 & 0.312 & 2.644 & 0.022 \\
\hline TKMS & 0.023 & -0.075 & 4.228 & 0.155 & 0.005 & -0.117 & 2.887 & 0.029 & 0.005 & -0.266 & 2.656 & 0.024 \\
\hline VAIN & 0.020 & 0.001 & 3.696 & 0.133 & 0.004 & 0.008 & 4.002 & 0.026 & 0.004 & 0.018 & 4.039 & 0.026 \\
\hline VAIV & 0.017 & 0.280 & 3.027 & 0.090 & 0.129 & -1.198 & 61.912 & 2.105 & 0.004 & -0.080 & 3.084 & 0.021 \\
\hline VAL1 & 0.022 & -0.229 & 4.655 & 0.158 & 0.004 & 0.110 & 2.427 & 0.017 & 0.004 & 0.158 & 2.465 & 0.017 \\
\hline VALK & 0.028 & 0.443 & 4.140 & 0.180 & 0.005 & -0.293 & 3.899 & 0.030 & 0.005 & -0.248 & 3.847 & 0.030 \\
\hline VANG & 0.019 & 0.050 & 4.440 & 0.127 & 0.093 & 8.302 & 79.974 & 1.216 & 0.005 & -1.400 & 8.955 & 0.038 \\
\hline
\end{tabular}


Monthly statistical analysis was performed for all of the stations (domes) for $4 \mathrm{~h}$ solutions, for 5-min averaged solutions (Eq.10) and the same with filtered solutions. The monthly Up statistics values of standard deviation, excess, asymmetry (skewness) and difference between max and min solution values were computed and results exposed in Table 4.

The Table 4 demonstrates the improved quality of filtered 5-min solutions against the 4h solutions. For example, KREI station, LIMB, LIPJ, REZ1, SALP, SIGU, SLD1 and others.

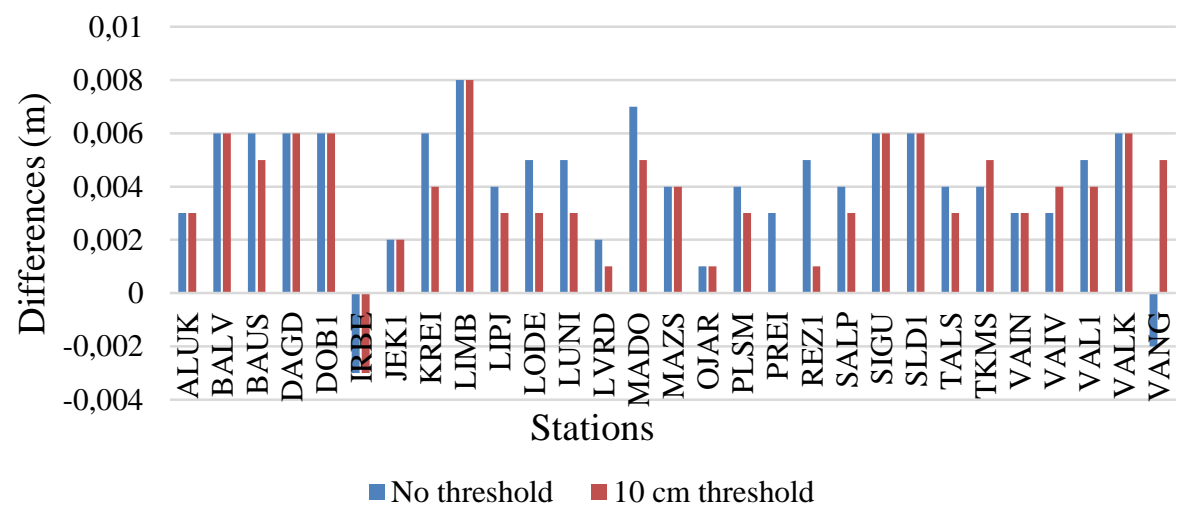

Fig.10. Comparison of Up differences between (4h solutions and non-filtered average 5-min solutions) and between (4h and filtered average 5-min solutions)

In Fig.10 the comparison of Up differences in solutions of Eq.11 of 5-min solutions in 2 cases: a) no threshold for 5-min solutions; b) $10 \mathrm{~cm}$ threshold for 5-min solutions of set $A$. In about $50 \%$ of 5 -min solutions the results are approaching to 4 h solutions. For SIGU and SLD1 stations the results have not changed in Fig.10 but statistics has slightly improved (Table 4).

\section{Helmert transformation to improve solution results}

GGI software of Helmert 7-parameter transformation model (Seeber, 2003) has been applied to reduce the processed station coordinates of both $4 \mathrm{~h}$ and filtered 5-min sets to the epoch 2015.0 (Eq.14):

$$
\left[\begin{array}{l}
X \\
Y \\
H
\end{array}\right]_{2015.0}=\left[\begin{array}{l}
\Delta X \\
\Delta Y \\
\Delta h
\end{array}\right]+(1+\Delta S)\left[\begin{array}{ccc}
1 & -R_{h} & R_{Y} \\
R_{h} & 1 & -R_{X} \\
-R_{Y} & R_{X} & 1
\end{array}\right]\left[\begin{array}{l}
X \\
Y \\
H
\end{array}\right]_{\operatorname{epoch}(j)},
$$

where 
$\Delta X$ - translation along the $\mathrm{X}$-axis,

$\Delta Y$ - translation along the $\mathrm{Y}$-axis,

$\Delta h-$ translation along the h-axis,

$R_{X}$ - rotation about the $\mathrm{X}$-axis,

$R_{Y}$ - rotation about the Y-axis,

$R_{h}$ - rotation about the h-axis,

$S$ - scale factor.

Two sets of all the 30 CORS stations were used for the Helmert 7-parameter transformation: a) set $S$ of epoch 2015.0 and 4 h set; b) set $S$ of epoch 2015.0 and filtered 5-min set of the corresponding day of December 2016 when the GNSS observations were gathered.

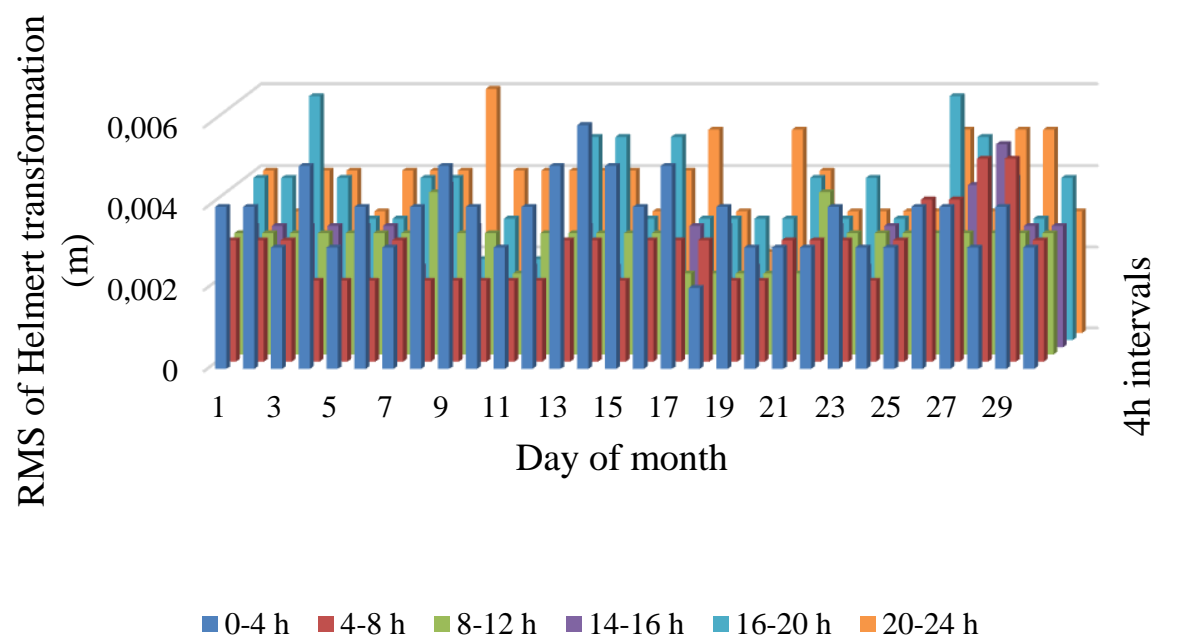

Fig.11. RMS (m) of Helmert transformation solutions from 4h observation epoch to the epoch of 2015.0 of the set of 30 stations

The RMS of transformation (Eq.14) solution for Up component of both 4 h set and filtered 5-min set were computed for each Helmert transformation solution. Results are depicted in plots of Fig.11 and Fig.12, correspondingly. To some extent the RMS explains the space weather influence to the observation result homogeneity in corresponding hours of days in December 2016. It is grounds to believe that the affected observation results in 5-min solutions were removed whereas they were not removed in the set of $4 \mathrm{~h}$ solutions. 


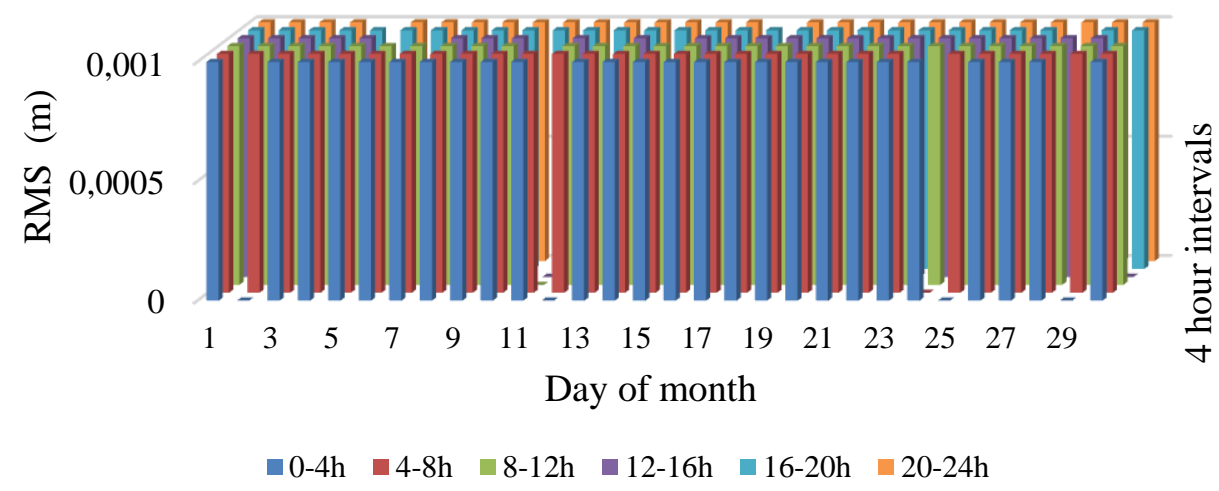

Fig.12. RMS (m) of Helmert transformation solutions from 5-min filtered observation epoch to the epoch of 2015.0 of the set of 30 stations

The final accuracy of each of the stations in each of the solutions were computed. The results are presented in Table 5 and Fig. 13.

Table 5. Improvement of the computation accuracy

\begin{tabular}{cclccc}
\hline$\#$ & Abbreviation & \multicolumn{1}{c}{ Solution } & Total & $\mathbf{1 5} \mathbf{~ m m}$ & $\mathbf{1 1}$ cm \\
\hline 1 & 4h & 4h & 5400 & $28.2 \%$ & $30.5 \%$ \\
2 & h_4h & Helmert transformed 4h & 5400 & $44.8 \%$ & $48.9 \%$ \\
3 & $48 \_5$ & Average 48 5-min & 5400 & $35.2 \%$ & $48.7 \%$ \\
4 & H_48_5 & Helmert transf.av. 48 5-min & 5400 & $49.2 \%$ & $55.3 \%$ \\
5 & $48 \_5 \_T 10$ & Prec. thr. 10 cm. av. 48 5-min & 5400 & $65.2 \%$ & $90.3 \%$ \\
6 & H_48_5_T10 & Helm. transf.av. prec. thr. 10 cm. av. 48 5-m & 5400 & $91.2 \%$ & $98.7 \%$ \\
7 & 48_5_T7 & Prec. thr. 7 cm. av. 48 5-min & 5400 & $65.3 \%$ & $90.3 \%$ \\
8 & H_48_5_T7 & Helm. transf.av. prec. thr. 7 cm. av. 48 5-m & 5400 & $91.2 \%$ & $98.7 \%$ \\
9 & 48_5_T4 & Prec. thr. 4 cm. av. 48 5-min & 5400 & $65.5 \%$ & $90.7 \%$ \\
10 & H_48_5_T4 & Helm. transf.av. prec. thr. 4 cm. av. 48 5-m & 5400 & $91.2 \%$ & $98.7 \%$ \\
\hline
\end{tabular}

Additionally, the filtration of 5-min (set $A$ ) solution results with threshold of $7 \mathrm{~cm}$ and $4 \mathrm{~cm}$, correspondingly were performed beside the $10 \mathrm{~cm}$ filtration mentioned above. The residual time series for Helmert transformation Up component were inspected. The residuals in both interval $\pm 5 \mathrm{~mm}$ and $\pm 10 \mathrm{~mm}$ were counted. In each of the cases 5400 solutions are analyzed. 
$120,0 \%$

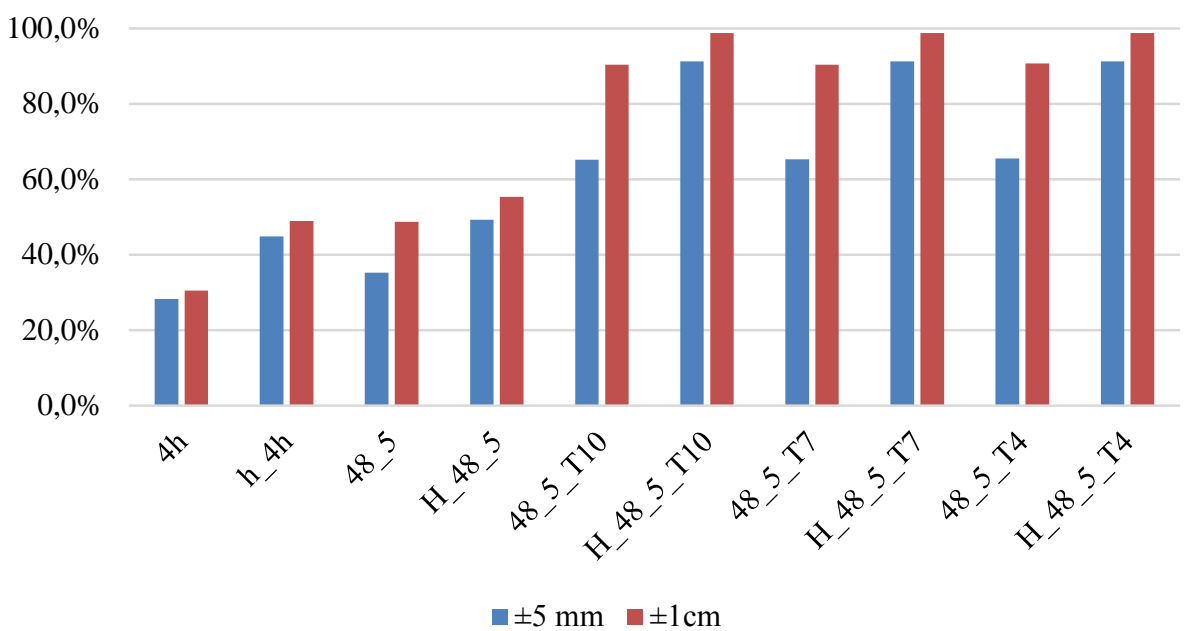

Fig.13. Improvement of the computation accuracy

The results are significantly improved in 5-min $10 \mathrm{~cm}$ filtered solutions (H_48_5_T10). According to the Fig.12 the computed coordinates coincide with an etalon values within precision of $1 \mathrm{~mm} .91 .2 \%$ of computed RMS doesn't exceed $5 \mathrm{~mm}$ after the application of Helmert transformation by reducing the 5-min filtered and averaged results to the applied epoch 2015.0 Table 5 and Fig.13).

It appears that results are practically not improved by changing the filtration threshold to $7 \mathrm{~cm}$ or $4 \mathrm{~cm}$, correspondingly, instead of $10 \mathrm{~cm}$.

\section{Conclusions}

The objective of this paper is to check the reliability of the 4 hour GNSS observation solutions at the continuously operating reference stations (CORS). Obviously, they are mainly affected by space weather and, probably, less affected by multipath due to the predominantly highly elevated placement of antennas which are not obstructed by trees or various constructions.

The mathematical GNSS observation reduction by using Bernese 5.2 software gives better results when splitting $4 \mathrm{~h}$ observation record in 485 -min records and kinematic reduction method is applied. It gives opportunity to remove outlying observation results influenced by space weather. The solutions of the 5-min set where the space weather influence is minimized by filtering gives the best final results. The improvement of 5min solutions is clearly visible by comparing Fig.5 and Fig.9. The Helmert transformation application gives additional improvement.

Unfortunately, it appears that at the formerly used Bernese 5.2 software solutions of 4h sets the space weather impact was not removed. 
It was assumed in this article that the results in CORS stations are mainly affected by space weather and less or even not affected by multipath due to the predominantly highly elevated placement of GNSS antennas. .It is worth noting that GNSS field observations on earth surface are often obstructed by trees or various constructions and consequently, they are additionally affected by signal multipath. In any case, it is important to take into account that for observations on ground the impact of both space weather and multipath are attendant. That relates not only for GNSS/levelling and other geodetic precise point positioning tasks but also for many positioning and navigation applications for cars, trucks, farming, construction, snow removal etc.

\section{Acknowledgements}

The research was developed under the contract ERAF No. 1.1.1.1/16/A/160.

\section{References}

Astafyeva, E., Zakharenkova, I., Förster, M. (2015). Ionospheric response to the 2015 St. Patrick's Day storm: A global multi-instrumental overview, In: J. Geophys. Res. Space Physics, 120, 9023-9037, DOI: 10.1002/2015JA021629.

Balodis, J., Varna, I., Haritonova, D., Normand, M., Silabriedis, G. (2017). Ground Based Kinematic GNSS Observation Results Affected by Space Weather Fluctuations in 2015, In: Baltic Journal of Modern Computing, Vol.5, No.3, 251-268.

Balodis, J., Silabriedis, G., Caunite, M., Janpaule, I., Balodis, K., Rubans, A., Aleksejenko, I., Otto, R., Ratkus, B., Reiniks, M., Mitrofanovs, I., Plotnikovs, S., Zvirgzds, J. (2009). EUPOS $^{\circledR}$-RIGA Network Elevation Analyses, In: International Symposium on Global Navigation Satellite Systems, Space-Based and Ground-Based Augmentation Systems and Applications, Berlin, Germany, 30 November - 2nd December 2009; Conference Proceedings. Senate Department for Urban Development, Berlin, Germany 2010; Publication ISBN 978-3938373-93-4; 68-72.

Béniguel, Y., Cherniak, I., Garcia-Rigo, A., Hamel, P., Hernández-Pajares, M., Kameni, R., Kashcheyev, A., Krankowski, A., Monnerat, M., Nava, B., Ngaya, H., Orus-Perez, R., Secrétan, H., Sérant, D., Schlüter, S., and Wilken, V.: MONITOR Ionospheric Network: two case studies on scintillation and electron content variability, Ann. Geophys., 35, 377-391, https://doi.org/10.5194/angeo-35-377-2017, 2017.

Cherniak, I., Zakharenkova, I., Redmon, R.J. (2015). Dynamics of the high-latitude ionospheric irregularities during the 17 March 2015 St. Patrick's Day storm: ground-based GPS measurements, In: Space Weather, 13 (9), 585-597, DOI:10.1002/2015SW001237.

Dach, R., Lutz, S., Walser, P., Fridez, P. (2015). Bernese GNSS Software Version 5.2. Astronomical Institute, University of Bern, Bern, Switzerland. 852 p.

Jinyun, G., Wang, L., Xin, L., Qiaoli, K., Chunmei, Z., Bin, G. (2015). Temporal-Spatial Variation of Global GPS-Derived Total Electron Content, 1999-2013, In: PLoS One. 10(7): e0133378, DOI: 10.1371/journal.pone.0133378. 
Morozova, K., Zarins, A., Balodis, J., Rubans, A., Jaeger, J. (2017). Digital zenith camera's results and its use in DFHRS v.4.3 software for quasi-geoid determination, In: Proceedings, 2017 Baltic Geodetic Congress (Geomatics). Gdansk University of Technology, 22-25 June 2017, Poland; 174-178, DOI: 10.1109/BGC.Geomatics.2017.74.

Seeber, G. (2003). Satellite Geodesy. Walter de Gruyter. Berlin, New York. 589 p.

Sreeja, V. (2016). Impact and mitigation of space weather effects on GNSS receiver performance, In: Geosci.Lett., 3 (24), 1-13, DOI: 10.1186/s40562-016-0057-0.

Zakharenkova, I., Astafyeva, E., Cherniak, I. (2016). Detection of the ionospheric plasma density irregularities by spaceborne GPS measurements, In: ESA Living Planet Symposium (9-13 May 2016, Prague, Czech Republic).

Zvirgzds, J. (2005). Global positioning system permanent base station network in Latvia, In: Scientific Proceedings of Faculty of Civil Engineering, Riga Technical University, 51-57.

WEB (a) Zak Kassas (2018). No GPS, No Problem: Exploiting Signals of Opportunity for Resilient and Accurate Autonomous Vehicle Navigation. http://itsnt.fr/index.php?onglet=17

WEB (b) ESA space weather awareness. 2017. http://swe.ssa.esa.int/

WEB (c). COMPET-5-2017-SpaceWeather. http://cordis.europa.eu/programme/rcn/701815_en.html

WEB (d) Schmidt M. 2018. Geodetic space weather research. http://www.ggosdays.com/en/focusareas/geodetic-space-weather-research/

WEB (e) https://www.nasa.gov/subject/3165/space-weather/

WEB (f). NOAA. Space weather prediction center. National Oceanic and Atmospheric Administration. http://www.swpc.noaa.gov/products/goes-x-ray-flux

WEB (g). EUREF permanent GNSS network. http://www.epncb.oma.be/

WEB (h). LatPos. http://map.lgia.gov.lv/index.php?lang=2\&cPath=2\&txt_id=13

WEB (i). EUPOS-Riga, Riga Municipality City Development Department. http://www.rdpad.lv/geotelpiska-informacija/eupos-riga/

WEB (j). SpaceWeatherLive.com https://www.spaceweatherlive.com/en/auroral-activity/top-50geomagnetic-storms

Received May 18, 2018, accepted November 11, 2018 